\title{
LAS DEMOCRACIAS COMO LOS BOSQUES
}

\author{
Tomás Rodríguez Villasante
}

L a idea de comparar a las democracias con los bosques surgió de los trabajos sobre ecofeminismo de Vandana Shiva. A semejanza de los ecosistemas, los elementos internos se pueden estar reforzando y generando sinergias y creatividad, o todo lo contrario. La cuestión es qué tipo de relaciones se están dando entre los elementos. Las democracias no pueden ser sólo unas declaraciones formales, un organigrama jerárquico, o unos procedimientos rutinarios y ceremoniales. Han de ser relaciones vivas capaces de poner en activo los valores de cada grupo que las compone. Y no sólo los grupos partidarios o los intereses económicos, sino precisamente la enorme creatividad popular que se está despilfarrando por falta de confianzas y cauces adecuados. Un bosque sale adelante cuando encuentra situaciones difíciles y agresiones naturales, aprovechando todos sus elementos tanto la fuerza de los grandes árboles y animales, del sol, como la de los pequeños animales y las plantas, o el agua que se filtra $o$ condensa.

Hay formas "jerárquicas" de democracia que se presentan ellas mismas como formas de estabilidad de los espacios públicos, donde se valora más lo conseguido que lo que se puede conseguir en un futuro. Hay otras

Tomas Rodríguez Villasante, director de varios posgrados en Metodologías Participativas y Desarrollo Local,con presencia en Chile, Ecuador, Perú y España. formas de democracia más "heterárquicas" en donde aparecen controles por rivalidades y alternancias de poder. En éstas no se cuestiona tampoco las formas de representación, pero sí quienes asumen por años tal o cual protagonismo. Cuando se prolongan las primeras formas sin entrar en sus problemas de fondo, suele aparecer algún momento de pánico, algunas movilizaciones, democracias "anárquicas", que cuando menos permiten cambios más en profundidad, aunque suelen durar poco, son poco estables. Hay otras formas de más "poliarquía" que parten de tener en cuenta las redes creativas de la sociedad, las nuevas prácticas instituyentes, incorporando así a las democracias participativas.

Las democracias participativas aparecen en casi todos los programas de los partidos políticos desde hace años como una síntesis de la democracia representativa y de las experiencias de democracia directa. Qué entienda cada partido, o cada alcalde, concejal, sin embargo, es de lo más variopinto que uno se pueda imaginar. No creo que valga la pena hacer aquí un recuento de las diferentes versiones teóricas para justificar lo que debería ser y lo que no es. Nos parece más interesante, a los equipos que venimos trabajando en estos temas, partir de las experiencias prácticas que se han venido dando en los diferentes municipios, y desde ahí ver cuánto hay de 
realidad en lo que se propone. A principios de los años 90 ya hicimos una investigación sobre unos 20 municipios que destacaban por sus prácticas participativas. Se publicó en la Revista Alfoz — que entonces existía en Madrid-y en un libro de ediciones HOAC, L as Democracias Participativas.

Precisamente ya entonces distinguíamos, a partir de los casos estudiados, entre la "participación ciudadana" y "las democracias participativas". Participación ciudadana se ha ido asimilando a una concejalía dentro de los ayuntamientos, que además de tener muy escaso presupuesto se encarga de las relaciones con las asociaciones, sobre todo las actividades culturales y reivindicativas de los barrios.

En su ámbito de discusión están los reglamentos de participación, las subvenciones a las asociaciones y actividades, y pocas cosas más, tanto hace diez años como ahora. Las propias asociaciones se encuentran muy metidas en estas lógicas de "reglamentitis" y "subvencionitis", como tuve ocasión de debatir en la reciente Convención de Badalona, con Asociaciones de Vecinos de todo el Estado [español]. Los Reglamentos y subvenciones, y las campañas de participación de los vecinos en las actividades públicas, son conquistas de la ciudadanía que no se deben perder, que hay que incrementar. Pero no constituyen el centro de la democracia.

Las formas de las democracias participativas, en cambio, muchos consideramos que están en el centro de la democracia local. Los ejemplos que estudiamos tanto aquí como en otras partes del mundo — desde Kerala, India, a Villa El Salvador, Perú; desde Porto Alegre, Brasil, a Londres, por ejemplo_- tienen otras características que sitúan a estas poblaciones como referentes de lo que es posible construir con los ciudadanos más allá de la democracia representativa. Para empezar se trata de experiencias muy diversas entre sí: municipios pobres, medios y ricos; pequeños y grandes; con muy diversas culturas; desde iniciativas populares o desde frentes de partidos, etc. Es decir, apenas se puede hablar de democracia participativa en singular, como un modelo de referencia, sino en plural de diversas vías o procesos de construcción según las características propias de cada lugar. No son reducibles a un reglamento tipo.

Otra característica es que implican a los departamentos municipales en su conjunto, empezando por la propia alcaldía. Las democracias participativas en unos casos parten de un monto de los presupuestos o de áreas como obras o urbanismo; en otros casos, de una concepción integral de la participación en todos los aspectos municipales, pero siempre con la voluntad de no quedar restringidas al debate de las subvenciones de tal o cual departamento. Tampoco se trata sólo de debatir con las asociaciones constituidas sino con toda la ciudadanía que quiera participar. Es decir, promover procesos para que nuevos sujetos sociales se sumen a las asociaciones ya existentes o creen otras nuevas, o simplemente recojan firmas o tengan una iniciativa ocasionalmente, incluso acudan a asambleas o talleres de diagnóstico y propuestas, permaneciendo el tiempo que quieran durar. No tanto reglamentados o subvencionados por el ayuntamiento como autoorganizados en las formas y tiempos que consideren más oportunos en cada situación particular.

\section{¿Quién hace las preguntas de la agenda?}

Algunos han venido a criticar tanto las democracias representativas, por lo que tienen de elitistas con la partidocracia, los abstencionismos, los clientelismos, las burocracias, etc.; como criticar también la participación de las asociaciones por lo que tienen de prolongaciones y repeticiones de los vicios citados. Y en muchos casos no les falta razón, pues desde las iniciativas ciudadanas no siempre se han propuesto formas alternativas de gestión y participación más ágiles, trasparentes, eficientes, etc. Pero esta situación ha justificado a veces reclamar la participación directa de los ciudadanos sin la intermediación de asociaciones ni partidos. Es decir, 
formas técnicas de consultas del tipo de referéndum, preguntas en programas de televisión o radiofónicos, formas de tele-democracia, Internet, o incluso los "núcleos de intervención participativa (NIP)", o las "iniciativas legislativas populares (ILP)".

Pero no todo es lo mismo en estas formas de participación directa, depende mucho de cómo se articulan para que puedan ser consideradas democracias participativas desde las experiencias analizadas. Sistemas autoritarios — incluidas dictaduras — han usado de los referéndum e incluso de sistemas asamblearios, más o menos masivos, y no por eso les vamos a dar el título de democracias directas. Porque cualquier consulta o debate en el que la información o las preguntas ya están restringidas de antemano son formas que nacen viciadas o sesgadas desde donde se convoca. Puede participar muchísima gente en las respuestas, tanto por votaciones como en asambleas multitudinarias, o por medios electrónicos más modernos, pero ¿quién dicta las preguntas? Las informaciones previas que circulan, de donde se seleccionan las preguntas, son clave, y éstas suelen sermanejadas por técnicos en la materia al servicio de los poderes y sus objetivos.

La cuestión por tanto habría que centrarla no tanto en cuántos han participado en las respuestas, sino en la elaboración de las preguntas. Es decir, cómo ha sido la agenda del proceso y quiénes son los que la han ido definiendo y realizando. Desde el primer momento, desde los síntomas iniciales, cómo se ha ido conformando el problema mismo, los objetivos, los tiempos y las metodologías, etc. No es igual una consulta popular que sale de la elaboración en talleres con participación pluralista o de una recogida de firmas con debate amplio de sus contenidos, que cuando surge de un estudio sociológico que ya conoce las posibles respuestas o de las intenciones de algunos poderes para legitimar su gestión. La tele-democracia puede ser un instrumento muy interesante, cuando previo a las consultas, sean democrático-participativas las formas de elaboración de las preguntas; y siempre que el acceso a estos medios esté generalizado, cosa que aún no ocurre suficientemente — ni en nuestras sociedades — para todos.

Los problemas hoy no son por técnicas a desarrollar o generalizar, sino por cómo se plantean los procesos metodológicos de forma que los ciudadanos en general sientan que es creíble lo que se dice y lo que se hace. Sobre todo lo que se hace, pues todos estamos ya cansados de declaraciones de intenciones y de diagnósticos más o menos críticos sobre la situación actual. Lo que se ve y nos lleva a la abstención tanto de la democracia representativa como de la participativa es la falta de resultados, aunque sean pequeños, entre lo que se hace y lo que se planteó inicialmente. La desconfianza está muy generalizada porque se habla mucho y lo que se hace se decide en otros lados, que son difíciles de saber para el ciudadano medio. La experiencia nos enseña también a todos que cuando hay una relación directa y clara entre lo que se hace —obras publicas, servicios, empleo, etc.y donde se plantea y decide, entonces la gente acude y las formas de participación se reclaman democráticas. Si no hay temas concretos que sean operativos, la gente — con razón-desconfía y se inhibe, no participa.

\section{¿Organigramas o sociogramas locales?}

Las cosas se deciden casi siempre en las redes de proximidad, de cotidianeidad, en las que nos movemos todos. Siempre estamos realizando nuestras pequeñas encuestas y sondeos con los amigos/as, la familia, los compañeros/as del trabajo o los vecinos/as. Después vemos que "todo el mundo dice...", por lo tanto cada cual en su mundo tiene sus referentes principales para las tomas de decisiones de cierta importancia. Esto lo saben las campañas de publicidad, las electorales, los medios de comunicación, y los dirigentes de los movimientos sociales. Son las "teorías de redes" que venimos usando las que nos dan cuenta sobre cómo funcionan todos estos entramados y tejidos sociales. Recientemente se habla 
de "capital social" y otros conceptos semejantes - no muy afortunados, pues las relaciones no creo que sean como el dinero acumulables_- pero lo que viene a significar es la importancia que están cobrando dichos planteamientos.

En la democracia lo que más se percibe son las elecciones o las asambleas, y pareciera que es ahí donde se deciden las cosas. Pero realmente es en los comentarios de las redes de cotidianeidad donde se están jugando las elecciones, o las acciones que se acuerdan en una asamblea. Si ponemos el ejemplo de una localidad o un barrio de 20000 habitantes y acuden a una asamblea 200 personas, aunque sólo esté allí un uno por ciento el comentario será que "estaba todo el mundo", y es que en esa proporción alguien de casi todas las redes seguramente estaba presente. Es decir, que para que acuda ese número de personas a la reunión tiene que haber corrido algún rumor, sido comentado en distintos ámbitos de la localidad, etc. Con sólo carteles o convocatorias habituales acudirían veinte y de los que acuden van a casi todas las reuniones, seguramente. Tiene que haber algo distinto en la convocatoria para que sea comentado en distintos círculos y convoque a más gente. Lo que sucede antes de esas reuniones es tanto o más importante que lo ocurrido en las mismas pero tiene la dificultad para los que convocan de que es menos controlable.

La pluralidad de comentarios que se generan en las casas, bares, parques, la parroquia, los trabajos, los comercios, el mercado, etc., son de una gran riqueza y por lo mismo la base de toda democracia. Ocurre que luego no siempre pueden o quieren expresarse en los ámbitos más sociales o políticos. En las elecciones, en medio de programas partidarios, han de escoger entre los mayoritarios con posibilidades, y no es fácil el diálogo o discusión de los comentarios de calle y los programas referidos. En los mítines o la información de los medios las consignas van en una sola dirección. Pero en las asambleas de los movimientos sociales tampoco suele haber espacios para la elaboración de las decisiones en pequeños grupos. Si tomamos el ejemplo de 200 personas reunidas, pocas de ellas se atreverán a hablar en público y con intervenciones cortas para no monopolizar las informaciones. De todas maneras lo que se debata ha de ser en torno a algunas cuestiones centrales para no dispersarse, aun así siguen perdiéndose los comentarios que sólo se podrán hacer antes o después en las redes cotidianas.

Se tomarán decisiones posiblemente relacionadas con alguna opinión mayoritaria, y los dirigentes que ganen saldrán convencidos de ello, pero en los días siguientes será en los comentarios informales donde se tome la verdadera decisión de acción y respaldo, o de desgana y delegación para que lo hagan los que ganaron. Por ejemplo, si el comentario es que "hablaron los de siempre, se pelearon tal y tal, y decidieron esto en contra de la otra propuesta..." es posible que la gente se muestre escéptica y espere a ver qué pasa. Pero también podría ser que se comente "a pesar de que están reñidos, van actuar juntos para este asunto...” y eso genere más apoyo desde la ciudadanía. Las redes cotidianas de comentarios deberían tener más importancia en las formas democráticas, pues son los micropoderes desde donde se puede y se debe construir la pluralidad. Es decir, partir más que del organigrama de ayuntamiento, con sus concejalías y comisiones para la participación, de las redes informales y formales de la ciudadanía, o sea, del sociograma y los conjuntos de acción. Conjuntos de acción por problemas concretos, de cada barrio o sector, que se organizan mientras dura la resolución del asunto.

\section{El miedo a la gente y la creatividad}

Por supuesto, muy pocos, y menos los políticos o dirigentes sociales, reconocen que tienen miedo a la gente. Pero ya son muchos los años de tratar con técnicos, dirigentes o concejales, y de escuchar 
expresiones de desconfianza en la capacidad de las gentes sencillas para entender y resolver los problemas de la administración. Por ejemplo, a los políticos les asusta llegar a un barrio y que, en la asamblea que convoca, algún vecino le interrogue con no buenos modales, o que un dirigente social le acuse públicamente de tal o cual problema. En ocasiones no les falta razón, pues ciertas intervenciones se plantean bruscamente $O$ sin salidas, o con demagogia sólo para quedar bien delante de los vecinos. Hay reuniones de barrio o de pueblo que se convierten en acusaciones entre dos personas para quedar uno por encima del otro, sin pensar en solucionar los problemas. Lo cual no sólo desgasta a ambas partes, sino que aburre y hace perder la confianza a los asistentes de ese tipo de reuniones.

Los técnicos también suelen asustarse, sobre todo cuando han de cambiar sus programas y rutinas, y ante todo se quejan si los vecinos no están preparados y opinan "tonterías". Ciertamentelos ciudadanos no tienen por qué saber de cuestiones técnicas, así puede conllevar que sus primeras opiniones fueran muy descabelladas. Pero las primeras opiniones de un proceso son los síntomas delos que hay que partir. No constituyen ninguna verdad irrebatible, ni las propuestas técnicas, ni las políticas, ni las de los ciudadanos: sólo deben ser las posiciones desde donde cada cual se pregunta cómo mejorar la calidad de vida. Queda por construir mucho camino, que no se puede hacer si no se sabe desde qué prejuicios comenzar. Sin duda se trata de superar las primeras impresiones, aunque el debate democrático sea eso, superar y concretar desde distintos enfoques lo que se quiere hacer y cómo hacerlo. Los técnicos municipales, como los médicos con sus pacientes, deben escuchar todos los síntomas, incluso en sus versiones más equivocadas, no para darles la razón, sino para construir desde esa realidad lo que se puede llevar a cabo democráticamente, o sea, no en contra de la población.

Hay métodos y formas prácticas para que las asambleas no se conviertan en riñas improductivas y desgastantes, para que los técnicos escuchen a la población, para que también los dirigentes salgan de sus asociaciones y sepan lo que plantean otros vecinos y colectivos. Porque también a muchos llamados dirigentes les cuesta salir a hablar con otros vecinos, de otras generaciones o culturas, con los que tienen ya prejuicios establecidos. De esta posición al corporativismo y al sectarismo sólo hay un paso. Y asíles van a muchas asociaciones que se encierran en símismas, y que únicamente salen a pedir subvenciones, acusando a los otros vecinos de no apreciar el gran trabajo y sacrificio que los primeros hacen desinteresadamente. Tras acusar a quienes no les secundan, lo que se esconde es no querer ir a escucharles en sus razones de fondo para no acudir a las asociaciones. Sin duda muchos de los razonamientos de la gente sencilla son contradictorios o falsos, pero es desde ahí donde hay que empezar a construir procesos democráticos, y no desde modelos ideales.

Existen formas para suscitar la creatividad social precisamente a partir de los primeros prejuicios y estereotipos que se manejan. Los primeros comentarios que se pronuncian en reuniones de este tipo suelen ser lugares comunes para no "meter la pata" y, por lo mismo, se suelen repetir argumentos que salieron en televisión, $\mathrm{O}$ también lo que cree la gente que debe estar mejor visto por el técnico en cuestión, o por el político al que se quiere convencer. Pero raramente salen las cuestiones de fondo si no es en un segundo o tercer momento, cuando ya hay cierta confianza y los primeros tanteos se han dado. Los procesos de creatividad social no parten de tipos geniales, sino de las paradojas con que nos encontramos todos los días. Lo más creativo no es inventar algo de la nada —además es imposible — sino aprovechar lo existente para encontrar y construir soluciones que aprovechen las posiciones de las mayorías. Las "segundas reflexividades", sistemas de talleres para hacer avanzar nuevas propuestas, han de ser participativas para ser creativas, más allá de las rivalidades tradicionales internas de cada lugar. No se trata exclusivamente de 
que los dirigentes o los técnicos sean creativos para que la gente participe, sino de que la gente participe para que pueda sentir que construye creatividad y proyectos viables por los que luchar. Es decir, sentirse protagonistas de sus propuestas.

\section{Ejemplos diversos y potencialidad local}

La historia de nuestros municipios nos ha dejado una serie de ejemplos de cómo se pueden hacer las cosas, sobre todo en algunos concretos. Citamos en su día a Santa Lucía de Tirajana, Canarias; Marinaleda, Andalucía; Arbucies, Catalunya, y otros gallegos, castellanos, etc. Casi todos vinieron a constituirse en las primeras elecciones democráticas locales de 1979 -España_, a partir de movimientos unitarios específicos y normalmente con un líder de fuerte personalidad incuestionado. Los partidos políticos en estas pequeñas provincias combativas quedaron en un segundo plano frente a las formas de democracia participativa. Lo que nos han aportado son interesantes propuestas de descentralización, a pesar de ser poblaciones entre 10000 y 30000 habitantes, aprovechando las asambleas de cada subzona y el sentido unitario de los movimientos sociales locales. El Reglamento ha sido desbordado por las prácticas de los ciudadanos o simplemente no existe porque se quedaría obsoleto ante la realidad del proceso.

Desde mitad de los años ochenta y a lo largo de los noventa han ido apareciendo en bastantes barrios de ciudades experiencias de Planes Comunitarios y otros programas de participación que rompen las lógicas paralizantes y sectorializadas de la mayoría de los ayuntamientos. Primero serán las metodologías de la "audición", de Marco Marchioni, en bastantes ciudades de la península ibérica y el archipiélago canario: luego cada barrio tratará de adaptar la propuesta a su situación particular. Aparecerán después los "núcleos de intervención participativa" que impulsara primero Hans Harms en el País Vasco, y luego las experiencias en Catalunya. Entre ellos, diversas propuestas de Programaciones de Acciones Integrales con formas y métodos muy diversos que se han ido impulsando en diferentes ciudades y barrios. Algún programa contra la drogadicción, algún plan leaderen zonas rurales, algún programa de participación ciudadana, algún plan integral de servicios sociales, etc., han sido las excusas para que desde varios servicios técnicos y algunas asociaciones se hayan ido innovando procesos que apuntan hacia las democracias más participativas.

Ya en estos años de cambio de siglo hemos podido apoyar desde distintos equipos la introducción entre nosotros de los Presupuestos Participativos. Siguiendo en gran medida el ejemplo de Porto Alegre, al igual que otros municipios brasileños. También nos planteamos cómo se podría hacer aquí en una realidad tan distinta. Primero fue Rubi en Barcelona, después continuó Las Cabezas de S. Juan, Sevilla, también Córdoba y Puente Genil están en este proceso. Los intentos de Sabadell y Albacete, aunque de menor tiempo en duración y profundidad, indican que ya se le empieza a perder el miedo a estas prácticas democráticas y que lo participativo va dejando de ser un rótulo en un programa para pasar a distintos tipos de acción con los ciudadanos autoorganizados. En el último año, Sevilla, Getafe, y algunas otras ciudades y pueblos de gobiernos progresistas están en la tarea de los Presupuestos Participativos. Pero los cambios son lentos, pues, después de siete años planteando estas posibilidades de democracias participativas, tan solo éstos son los ejemplos que nos atrevemos a presentar. Si juntásemos todas las experiencias exitosas de pueblos y barrios con intentos democráticoparticipativos se puede llegar a medio centenar más o menos, lo cual dice que son pocas refiriéndonos al gran número de municipios que existen en el estado español, pero al menos deja ejemplos de que en cada 
Autonomía hay algunas experiencias que merecerían ser reconocidas y emuladas, aunque no copiadas.

En todos los casos siempre se trata de procesos originales adaptados a cada situación concreta, basados en la voluntad política de los ayuntamientos, la articulación de las asociaciones sin demasiadas rivalidades, el acompañamiento de técnicos contratados o de universidades, y la incorporación de nuevos sectores de ciudadanos/as. Cuando se dan estas condiciones siempre resulta más fácil arrancar, a veces falta alguno de los componentes, entonces hay que procurar incluirlo. Por eso las nuevas metodologías sobre democracias participativas están ahora abriéndose camino. No es una cuestión sólo de buena voluntad, aunque sin ella desde luego no se puede apenas avanzar. Tampoco es una metodología que se pueda aplicar como receta en cualquier lugar. Hay que partir de qué preguntas se hacen los propios ciudadanos, partir de síntomas a veces preocupantes y críticos, de situaciones paradójicas y no esperadas; de forma que se demuestre que no hay miedo en la gente, que se quiere y se sabe escuchar, y que se confía en la creatividad social de las democracias participativas.

\section{Democracias y presupuestos participativos}

En varios municipios y algunos estados hace más de una década que se viene debatiendo acerca de los Presupuestos Participativos. Sobre todo, referido a los modelos que se iniciaron en Brasil, donde se ha puesto a debate en asambleas populares la nueva inversión pública para el año siguiente con la voluntad del gobierno y la participación activa — con propuestasde miles de ciudadanos - tanto asociados como no asociados - Se trata de una facultad que tiene cualquier gobierno para elaborar sus presupuestos consultando a los técnicos que crea conveniente o, como en este particular, dejándolo en manos de las asambleas de ciudadanos y los técnicos que les apoyan en temas participativos y económicos.

Desde febrero hasta noviembre se convocan una serie de asambleas descentralizadas y reuniones de delegados. En ellas se aborda un autorreglamento que cada año se revisa, donde los ciudadanos — organizados o no-son los que deciden los cambios. Cada año se empieza por revisar la consecución de obras y servicios que se presupuestaron y su grado de cumplimiento. En las siguientes asambleas se proponen los criterios y prioridades para el año entrante, según tablas de necesidades y opiniones de los asistentes, a partir de las iniciativas presentadas. A los poderes electos les toca: a) poner sus técnicos al servicio de la población - dinamización y autoformación descentralizada, información económica y técnica, etc.-; b) votar en el Pleno del organismo las propuestas de la población sin cambiarlas; y c) ejecutar lo acordado con la población y celebrarlo conjuntamente.

Los ejemplos de municipios brasileños son los más conocidos, sobre todo Porto Alegre, capital del estado de Río Grande do Sul, de un millón y medio de habitantes, que desde hace más de una década ha hecho de esta forma innovadora de hacer política su seña de identidad. Por otro lado, Villa El Salvador, Lima, municipio de 300000 habitantes, desde hace 30 años viene siendo pionero en formas de superar la pobreza y ahora desarrolla un modelo interesante de Presupuesto Participativo, ya que en Perú ha pasado a ser una recomendación del Estado el que se haga en todos los municipios. Lo importante es que ya estemos pasando de debatir abstracciones y deseos de participación, a cuestiones más concretas y creíbles como son estos ejemplos. En Sevilla, siendo el primer año de prueba y poniendo a discusión publica sólo 5\% del presupuesto a modo de ensayo, se han llegado a concentrar 3000 personas en las asambleas sobre propuestas para el año 2005. Pero lo más interesante es que se presentaron más de 100 iniciativas desde las bases, tanto de las 
asociaciones más tradicionales, como desde sectores independientes de ciudadanos — vinculados tanto a los deportes, como al feminismo o sectores culturales-. Sin duda es una forma de empezar, pero lo que más cuenta no son los resultados cuantitativos, sino las ganas de sectores tan dispares de ponerse a renovar la esfera de lo público desde las bases más informales. En un evento realizado con las universidades de Sevilla, mayo de 2004, para apoyar los Presupuestos Participativos, tuve la ocasión de proponer estos postulados para la renovación de la vida democrática; no como objetivos idealistas, sino como lo que podemos aprender de algunas experiencias ya en marcha.

\section{Una nueva forma de hacer política}

\section{Democracia transparente}

Se trata de superar las reuniones de los despachos y las relaciones bilaterales entre cada partido y las asociaciones, para llegar a unas relaciones horizontales y de mayor transparencia entre las asociaciones, incluye también a los no asociados de la zona o tema que esté en discusión. Es decir, una nueva cultura no corporativista basada en el universalismo de las redes sociales, en el debate de las propuestas por sí mismas más que en la delegación. Propuestas concretas para realizarse el año siguiente; así como la supervisión de este proceso.

\section{Democracia pedagógica}

Superadas las luchas mediáticas y propagandísticas de los programas se pasa a la autoformación cívica de los participantes para que sean ellos los que vayan decidiendo en lo concreto. Se toma en cuenta tanto los límites de los presupuestos como la solidaridad con los menos favorecidos. Se trabaja en los talleres participativos de los barrios con los "grupos motores" y en "caravanas" que visitan cada barrio y cada propuesta sectorial, por ejemplo.

\section{Democracia solidaria}

Pasar del asistencialismo a sectores sociales tradicionalmente excluidos —mujeres, jóvenes, inmigrantes, etc. - a cuotas que permitan una presencia activa de las iniciativas de base, y que éstas sean propuestas defendidas y supervisadas por los delegados de dichos sectores ante el conjunto de la ciudadanía. Se puede, de esta manera, potenciar positivamente el debate y acuerdos desde la perspectiva de género, desde lo intergeneracional y lo intercultural.

\section{Democracia operativa}

Donde trata de "bajar" a propuestas concretas y operativas las promesas y grandes discursos que se suelen pronunciar en las campañas electorales. En estas asambleas hay que hablar de criterios y prioridades jerarquizados y no de todo lo que nos gustaría tener. Se proponen obras específicas para realizar el año siguiente y las partidas presupuestarias que se van a aprobar y supervisar por los delegados responsables de cada obra.

\section{Democracia creativa}

La agenda de cuestiones a discutir y proponer no la hacen ni los medios de comunicación ni los políticos, sino que descentralizadamente surge de las iniciativas de cualquier grupo o ciudadano que quiera acudir al proceso. Es la labor de los grupos motores de iniciativas, y de los técnicos que les apoyan, el poner en la agenda de los medios de comunicación y de los políticos lo que vaya surgiendo de las bases, tanto si es una recogida de firmas de unos particulares, como la realización de un Plan integral en un barrio o una propuesta sectorial para toda la ciudad. 


\section{Democracia instituyente}

Más allá de los reglamentos otorgados por los poderes a las asociaciones, se pasa a los auto-reglamentos revisables y a los delegados revocables, cada año, para cada tarea concreta. A la democracia instituida le surge una dinamización que le produce anualmente energía nueva, tratando de dejar los debates personalistas o partidistas fuera de juego, y complementando —desbordando, a veces_ — los viejos usos que se suelen criticar de las democracias anquilosadas.

\section{Los desbordes de técnicos y vecinos}

Pero, como venimos insistiendo, no se deben plantear los problemas de las democracias participativas como deseos bien intencionados, sino a partir de los actores reales y sus problemas cotidianos. Al menos hay que tener en cuenta a los políticos, a los técnicos y a los vecinos: unos y otros, más jóvenes o más maduros, no asociados o asociados, o en colectivos informales, distintos tipos de barrios y pueblos, etc. Así que vamos a tener en cuenta polémicas que están surgiendo entre los presuntos protagonistas de las nuevas experiencias, tanto de Planes Comunitarios como de las otras formas que apuntan a las Democracias Participativas. No sólo es un problema de los políticos, sino que tanto los ciudadanos organizados como los técnicos tenemos algunas cuestiones que resolver.

Principalmente en los últimos diez años observamos una polémica considerable entre Asociaciones de Vecinos y técnicos municipales por la gestión de planes de barrio, de competencias y apoyos económicos, y similares. Se puede generalizar este debate interno, de pequeñas políticas locales, a las distintas maneras de enfocar los movimientos sociales ante unos nuevos métodos y estilos de entenderlos para comprometerse en acciones transformadoras. También se puede aprender de algunas experiencias que ya se practicaban hace muchos años, y de nuevas metodologías que se están experimentando en nuestras ciudades y comarcas.

Para empezar creo que hay que huir de dos tópicos sobre los movimientos sociales y las programaciones participadas que arrastramos de décadas anteriores. Por un lado, en los años 60/70 parecía que los movimientos sociales y especialmente los ciudadanos siempre teníamos razón. Una literatura bastante optimista de técnicos y de vecinos coincidía en que estábamos transformando las ciudades y el mundo con distintas estrategias, según unos u otros, pero que la historia acabaría dándonos la razón de alguna manera. En los años 80/90 las realidades y los "estudios de caso" nos fueron convenciendo de que hay mucha complejidad en todo esto, y que las cosas no eran tan lineales. Cierto que nuestras ciudades se recuperaron gracias al esfuerzo de los movimientos y a las políticas locales que fueron sus consecuencias lógicas. Pero también hay que decir que desde mediados de los años 80 las crisis de las asociaciones de todo tipo nos llevaron a una fragmentación y un vacío de activistas muy notable.

Así, empezaron a aparecer análisis muy críticos de parte de los dirigentes que se eternizan en las juntas directivas, la burocratización de las asociaciones, etc. Escribí hace años, y en el presente este artículo se plantea al principio, de algunos males que ya nos aquejaban: "subvencionitis" — exceso de vivir de las ayudas"reglamentitis" — más pendientes de los ayuntamientos que de las bases sociales_- y "participacionitis" — que vengan a mi asociación, más que ir yo donde está la gente- Otros estudios de lo que pasa en los barrios y con los movimientos han sido más duros, y en algunos casos no sin falta de razón. En suma, se generalizaron diversas críticas que han contribuido tanto a un estado de queja permanente dentro de algunos de los movimientos por la falta de renovación, como de alejamiento de los mismos por parte de muchas personas, pues veían en ellos afanes de protagonismos 
o personalismos, peleas por situaciones no aparentemente importantes, etcétera.

Detrás de algunos reclamos a veces se ha escondido una justificación para no hacer nada o muy poco a favor de la transformación social. Siempre es posible hacer críticas a cualquier proceso. Lo más complejo es razonar las causas y atreverse a proponer estrategias y salidas viables. En varias ciudades han coincidido en estos años la polémica de los vecinos y los técnicos en torno a los planes Urban y Leader, Agenda 21, Planes Comunitarios, Presupuestos Participativos, etc. ¿Hemos de hacer la crónica de un fracaso anunciado? ¿Estamos condenados por la historia a no entendernos, como antes estábamos abocados a la "unión hace la fuerza"?

Siempre han existido personalismos y protagonismos, y siempre nos hemos encontrado "gorrones" y "trepas" en los movimientos; de la misma forma que también han sido y son auténticas "escuelas de ciudadanía". Si hablamos de los técnicos, siempre han estado en torno a los movimientos, o incluso dentro. Unas veces aprendiendo y otras dando un punto crítico saludable. Entre los técnicos como entre los vecinos hay de todo, y sólo el tiempo nos va enseñando cuál es el estilo, los intereses y la ética de cada quien. Pero eso se sabe después, ya que sólo con la práctica se puede demostrar a dónde nos llevan los movimientos. Lo que sí hemos aprendido es que no siempre nos llevan a buen puerto, y que tenemos que aprender también a sistematizar nuestras experiencias para no repetir errores del pasado. Ahora hay formas y estilos nuevos que muestran otros caminos.

\section{Nuevo ciclo generacional}

Hay ya varios análisis que muestran que los movimientos sociales tienen ciertos ciclos de vida, aunque no es el momento de pararnos a discutir esto. Lo que sí parece claro en nuestra realidad más cercana es que el tipo de movimientos que vivimos la generación que ahora tenemos más de 45 años, tiene poco que ver con esos otros movimientos en los que se incorporan los menores de 35 años. No sólo porque han cambiado las reivindicaciones o las motivaciones sean distintas, sino también por el tipo de asociaciones que crean, el estilo de hacer las cosas, etc. El salto generacional entre los que ya somos padres y abuelos y los que son hijos y nietos, no es sólo recurso que comentamos habitualmente, sino algo que afecta a los cambios dentro y fuera de los movimientos sociales, y por tanto a las formas de democracias que se están construyendo.

Conviene recordar los años 60, cuando jóvenes entonces peleábamos dentro de las Asociaciones de Cabezas de Familia — franquistas_- otros dentro de los sindicatos "verticales", etc. Había mucho de enfrentamiento cultural entre dos generaciones. No todo era política antifranquista. La generación de la guerra y la posguerra no nos entendía ni nos dejaba espacios para realizar nuestras actividades. Aunque ahora muchos presidentes de asociaciones sean de "izquierdas" tampoco suelen entender las nuevas formas de los más jóvenes. Y siguen quejándose de que éstos colaboran poco, que ellos son los imprescindibles y por eso no pueden dejar los cargos directivos... Si recordáramos los de nuestra generación aquellos años donde éramos jóvenes, tal vez veríamos similitudes con lo que está ocurriendo actualmente.

Hoy hay muchos jóvenes técnicos que desearían colaborar con asociaciones y con movimientos, bastantes lo están haciendo. Unos cobran y otros no, pero también entonces no todos eran voluntarios, aunque la situación de empleo era mejor y la democrática peor. Hoy la situación democrática es mejor pero el empleo es menos seguro y más precario para todos. Así que no ha de extrañarnos que la gente quiera cobrar y también vivir de hacer un servicio a la comunidad. No siempre es posible y muchas veces o se cobra muy poco o no se cobra, pero eso ya depende 
de unas u otras circunstancias y de los estilos de cada cual. Creo que no es bueno en esto generalizar, ni para todos los jóvenes ni para todos los técnicos. De la misma manera que no todos los vecinos son tan altruistas, y no sacan beneficios personales, de tipo político o incluso económico. Ya aprendimos que hay de todo, aunque la mayoría sean activismos bien intencionados.

Ya en los años de lucha contra el franquismo y en la "transición democrática" no era tan fácil separar quiénes eran técnicos y quiénes vecinos, pues había bastantes técnicos que aprendimos siendo activistas vecinales, $\mathrm{y}$ otros muchos vecinos que se formaron como técnicos en vivienda, por ejemplo en la organización de cooperativas, educación política, etc. Uno de los factores de éxito de aquellas luchas seguramente fue no hacer distinciones demasiado claras entre unos y otros, y colaborar más allá de las diferencias. Seguramente porque veíamos que el enemigo era muy fuerte y duro, y que no estaban las cosas para peleas internas que nos debilitaran. Por supuesto que todos sabíamos en qué trabajaba cada uno y cuál era su especialidad, pero juntos y revueltos había una división de papeles en función de la eficacia colectiva que no siempre se recuerda, y que de forma rotativa muchas veces nos permitió conseguir algunos logros.

En el nuevo ciclo generacional, que se inicia principalmente en los 90 , hemos intentado sumar a los jóvenes técnicos en la experiencia de los mayores. Quizá los más adultos se quedaron recordando las formas de lucha que aprendieron en décadas pasadas y de ahí les cueste salir, y quizá los más jóvenes no tienen la paciencia de aprender de los mayores. No me parece una situación nueva. Pero creo observar que la diferencia no es tanto porque unos sean vecinos del barrio y otros de fuera que sólo vienen porque les pagan. Sino que se trata de una diferencia de enfoques culturales y de estilos de trabajo que tiene más que ver con cada generación y sus circunstancias.
En Córdoba, a finales de los 80 y principios de los 90, ya me plantearon en la Federación de Asociaciones de Vecinos y en los Centros Cívicos, un conflicto donde el Reglamento no dejaba claro cuáles eran las competencias de cada quien. Mi respuesta fue que dejaran tranquilo el Reglamento y que formaran equipos en cada barrio para hacer un Programa de Acción Integral por cada zona. Técnicos y vecinos en "grupos motores"(GIAP) en el que participaran todos según el tiempo que quisieran y el tiempo que dejara el ayuntamiento a sus técnicos. A finales de los $90 \mathrm{y}$ principio de este nuevo siglo, en Madrid, comisiones de jóvenes vinculados a movimientos antisistema y antiglobalización también se vinculan con las Asociaciones de Vecinos, y no sabría decir cuánto tienen de activistas y cuánto de técnicos. Hay muchas otras experiencias que se haría largo de contar, aunque sean minoritarias - hace año y medio en la Convención Vecinal de Badalona se pudieron ver varias.

\section{Otros estilos y métodos son posibles}

Frente a una división del trabajo muy especializada entre "expertos temáticos" o técnicos, y "expertos convivenciales" o ciudadanos, hemos venido tratando de organizar "grupos de tarea", "grupos motores", "grupos de investigación-acción-participativa", en los que cada cual sabe su tiempo disponible, lo que puede aportar, y lo que obtiene - los demás también-. Pero el grupo se centra en una tarea conjunta, en mover un Plan de acción integral, sea Agenda 21, plan Leader —rural—, Plan Comunitario, Presupuesto Participativo, etc. Y no sólo estos grupos, sino también Foros, Coordinadoras, Comisiones de Seguimiento, o bien Plataformas más amplias donde están técnicos, vecinos y hasta políticos. En todos ellos no se resuelve la condición humana de cada persona o su estilo de hacer las cosas, pero sí el que se trabaje más unidos y se apunte a construir democracias participativas. 
El objetivo de todos estos grupos es aprender conjuntamente. Un primer indicador de que la tarea va bien, es que unas y otras personas — cada cual desde su diferencia "experta”-, están aprendiendo del propio proceso y de las iniciativas de los demás. Lo que solemos llamar "dejarse desbordar" por un buen ambiente creativo e ilusivo. El que sean heterogéneos los grupos, tanto los de actividad semanal como los de actividades mensuales u otras, se puede ver como una complementariedad saludable y no sólo como una rivalidad a ver quién tiene más protagonismo.

Siempre ha de existir un cierto interés por ser protagonista de estos procesos. No es cierto que sea enteramente desinteresado el participar en los movimientos sociales. Cuando menos se busca la satisfacción altruista de tener la conciencia tranquila por preocuparse de los asuntos colectivos. Todos queremos que nos den una palmadita en la espalda y que nos digan "qué bien lo estás haciendo". No veo nada malo en ello, y creo que deberíamos darnos muchas más palmaditas, además de hacer muchas más fiestas. Pues si no actuamos ni por acumular poder ni por acumular dinero, debemos hacerlo por acumular afectos y tiempos creativos. $\mathrm{Al}$ menos es lo que nos mueve a muchos. Aunque no queramos acumular, sí queramos un poquito de poder para que las decisiones se lleven a buen término, y otro poquito de dinero para no morimos de hambre. Aclarar estos puntos ayuda a saber cuáles son los intereses de cada uno, y a que el "juego" sea más limpio y democrático.

Así, pues, parece muy razonable que los ciudadanos/as que no cobran, y que ponen su esfuerzo voluntario, tengan derecho a protagonismos y fotos en los procesos. Pero no a imponer a los técnicos cuál es su visión como si fueran los únicos legitimados para hacerlo. Ya que tienen una visión parcial de su convivencia en la zona y el tema, al igual que los técnicos tienen una visión parcial según sea su especialidad y experiencia. Se necesitan para complementarse.
También parece razonable que los técnicos tengan su estrategia profesional para tener un sueldo adecuado y poder escribir, por ejemplo, ponencias para congresos, etc. En no pocos casos la colaboración y ayuda mutua hace que cada experiencia, además de ser útil para los ciudadanos de a pie, lo sea también para los dirigentes y los técnicos. Cuando no colaboran en los "conjuntos de acción ciudadana" es cuando no sirve para ninguno de los implicados, empezando por la gente de la base.

Hemos puesto en marcha algunos métodos, en reuniones y talleres, con los que trabajamos algunos técnicos para minimizar los personalismos. Lo primero es evitar los grandes discursos de "los que saben" sean dirigentes o técnicos-, y que éstos manejen la información que dan a los demás. El papel del técnico será, por ejemplo, poner un papel grande en una pared y coordinar las aportaciones con pequeños papelitos adhesivos, sin firmar, de cada asistente o cada grupo que se ha formado en la propia reunión. De tal manera que tanto los dirigentes como los no dirigentes opinan, o en todo caso convencen a los grupos pequeños en que se dividen las asambleas. Muchas de estas técnicas les parecerán a muchos simples juegos, pero tienen en sí dinámicas democráticas de importante contenido, sobre todo para recoger las aportaciones de los que no suelen hablar, tanto técnicos como ciudadanos. No se trata ni del técnico estrella ni del que se cree dirigente incuestionable. Se trata de construir con la aportación de la mayoría de los asistentes a cada reunión. Los "sociogramas", los "flujogramas", o los más conocidos "DAFO" o "árbol de problemas" y otros métodos, nos ayudan a elaborar procesos más abiertos y creativos.

Pero la clave no está en las técnicas aunque sea bueno familiarizarnos con ellas y para saber usarlas. La clave está en la "democracia interna" del proceso, del plan de acción integral, comunitario o sectorial. Hay que acostumbrarse a que casi todos "mandan". Sin duda los ciudadanos quieren mandar, si no no participan; lo que no quiere decir que sólo ellos manden. No hay 
participación sin toma de decisiones reales y no sólo consultivas. Pero los técnicos también tienen que mandar, sobre todo en los métodos y procedimientos participativos para que el proceso no se encapsule mirándose el ombligo los dirigentes. Y hasta los políticos han de mandar, pues normalmente es con ellos con quienes hemos de pactar la ejecución de lo acordado. Si una de las tres partes no se deja desbordar para aprender en el proceso es que el método no está funcionando. De esto se da cuenta la gente de la calle, común, que tienen fino olfato para ver las peleas o los entusiasmos de los que convocan.

Se está abriendo un nuevo tiempo generacional de movimientos sociales, tanto en el ámbito local como mundial. Pero las bases no son las mismas, pues el mundo ha cambiado mucho en estas décadas. Lo que sí continúa parecido es que hay que sumar las nuevas formas y personas que se incorporan y están pidiendo paso - tanto activistas como técnicos- A los que tenemos más de 50 años, lo que nos toca es hacer de puente, tratar de entender el nuevo ciclo con sus formas más concretas, aportar alguna comparación histórica, animar a aprender de todos lo que aportan. Quizá nos encontremos más en los tiempos de los Presupuestos Participativos que en el de los Reglamentos municipales, más en los Programas de acción integral que en Planes tradicionales, más en Foros Sociales que en las Federaciones, más en conjuntar Redes de movimientos que atender a cada corporativismo asociativo, etc. Pero, en definitiva, lo importante es demostrar prácticamente que los movimientos se mueven y que nosotros disfrutamos cuando construimos estas experiencias de participaciones democráticas y democracias participativas.

\section{Bibliografía}

Blanco, I y Gomá, R., 2002, Gobiernos Localesy Redes Participativas, Ariel, Barcelona.

Ganuza, E. y Alvarez, C., 2003, Democracia y Presupuestos Participativos, Icaria, Barcelona.

Garrido, F.J. y Villasante, T. R., 2002, Metodologías y los presupuestos participativos, IEPALA, Madrid.

Genro, T. y De Sousa, U., 2000, Lospresupuestos participativos, Ed. del Serbal, Barcelona.

Marchioni, M., 1994, La utopía posible, Benchomo, Canarias.

Sousa Santos Boaventura, 2003, Democracia y Participación. El ejemplo de Porto Alegre, El Viejo Topo, Barcelona.

Villasante, T. R., 1995, L as Democracias Participativas, HOAC, Madrid. Villasante, Montañés, Martí, 2000, La investigación social participativa, El Viejo Topo, Barcelona.

—, 2001, Prácticas locales de creatividad social, El Viejo Topo, Barcelona. 